MARTIN, Fran. "Overseas study as zone of suspension: Chinese students renegotiating youth, gender, and intimacy" Journal of Intercultural Studies 39.6 (2018): 688-703.

Accepted draft

\title{
Overseas study as zone of suspension: Chinese students re-negotiating youth, gender, and intimacy
}

'The pressure [to marry by a certain age] does decrease, over here [in Australia]. [...] It really does all get delayed by a few years, including settling down in a job; falling in love and getting married. [...] I feel that in those few years, anything could happen. If your way of thinking changes, then maybe your career will turn out to be the centre of your life; maybe the whole system will change [for you]. [...] You may think that you don't have to do things [the standard] way, like, quickly get married and settle down when you're 25; there's no need to. I'm actually pretty scared, pretty scared of settling down.

Super scared! [laughs] [...] Within myself I still sort of reject the expectations society places on adults. [...] Personally, I think that if you're economically independent, and make your decisions for yourself, then you [can be considered] an adult. [...] But there's a contradiction. On one hand this is how I think, but on the other hand I want other people to think I'm outstanding (优秀 youxiu). So in that respect, what others expect of me, I also expect of myself. [...] So I'm in a very contradictory period right now. Three years ago when you interviewed me, [...] I thought I could do whatever I wanted. Right now, I'm entering this contradiction. [...] I'm realising what society expects of people.'

- Song, $25^{1}$

\section{Introduction}

Song is a young woman who travelled from her hometown, a large city on China's east coast, to Melbourne for undergraduate study eight years ago, and remains there today. At the time of our last conversation, she was working as an IELTS tutor following her graduation with a Master of Teaching, while concurrently studying toward a Certificate qualification in the area of her new passion: personal fitness training. She had a boyfriend, also from China, but no firm plans to get married, preferring to hold onto the sense of personal space she enjoys in the inner-suburban single-bedroom apartment where she lives alone. Song's reflections touch on a number of points that 
link to key questions I will explore in this article. First, she makes the observation often repeated in my conversations with other Chinese student respondents in Melbourne - that studying abroad tends to delay the standard life course for women, adding some extra years in one's twenties before (it is generally assumed) one finally settles into stable employment and, ultimately, marriage and childbearing. Second, however, Song frames those extra years as a liminal time of nebulous possibility (Cwerner 2001: 27-28): if being away from China allows one's thinking to change enough, then 'anything could happen,' including a decisive shift away from a standard feminine life script hinging on marriage and family. Third, Song underlines what she presents as her own personal, independently decided indicators of adulthood, which centre capacities of the individual: economic independence and autonomous decisionmaking. Fourth, however, she highlights the contradiction between these and 'society's view' of the expectations of adulthood. The social expectations to which Song referred here largely concerned the assumption that a woman should get married and 'settle down' before the age of thirty. Although living in Australia and hoping to stay there permanently, at other moments in our conversation when Song spoke about her awareness of such expectations she mainly cited reference points in China: her mother's hopes for her; the life pathways of similar-aged female friends in her hometown of Nanjing. While living in Melbourne, Song had for several years felt distanced from those expectations. She told me that her formation of an alternative view of a desirable life course had been influenced on the one hand by her distance from dominant social opinion and familial pressures in China, and on the other hand by the greater diversity of life patterns that she observed in Australian society. Song's distancing from Chinese social expectations, however, was turning out to be temporary: at 25 , she had entered a phase of sharp contradiction between her own views and normative expectations about the script an adult woman's life should follow.

Following the cues of these four points, this article draws on my in-progress research with young women students in Australia to consider how time studying abroad may function as a 'zone of suspension' in both temporal and geographic terms for mobile young women like Song, in which they renegotiate the meanings of youth, feminine gender, and intimate relationships. ${ }^{2}$ China's young generation of middle-class urban women like Song, born after 1990 - known in Chinese as the 'post-'90s' (九零后 jüling hou) - are subject to the competing pull of at least two sets of contradictory ideologies. As I have elaborated elsewhere (Martin 2014), vis-à-vis gender, on one hand 
they are attracted by an emergent ideology of self-entrepreneurial, individualised selfhood; while on the other hand they are subject to the effects of re-traditionalising gender roles in the post-socialist era, whereby adult women's identity is (re)constructed as properly focused on the family rather than the self or the wider social collective (see also Wu 2009; Liu 2014). Relatedly, as I explore in this article, vis-à-vis life script, on one hand these young women are affected by the fairly rigid normative life-stage model of the elder generations, which is more compressed for women than for men and leaves them little leeway for deviation between stages; while on the other hand they are drawn toward a more open understanding of life course, incorporating a greater diversity of possible life pathways, and an extended transition to adulthood that may include premarital intimate relationships. This article explores how time spent studying and living abroad may affect young women's negotiation of this latter contradiction.

In pursuing this question, I interrogate the uses and limitations of Jeffrey Arnett's 'emerging adulthood' concept (2000) in accounting for these young women's experiences. Arnett's concept, introduced in detail below, is highly influential across much social sciences scholarship on life course and life transitions, and superficially, the patterns that emerge from my research with the Chinese students may appear to conform to this model. However, deeper consideration of my participants' experiences suggests that to apply Arnett's model uncritically would be to risk false universalisation, since it is clear that for these young women, both gender and ethno-cultural background place significant limits on the 'freedoms' supposedly typical of the emerging adulthood period.

\section{Method}

The material presented here is drawn from a longitudinal ethnographic study, funded by the Australian Research Council and still in progress at the time of writing, in which I am following 56 female tertiary students through several years of study in Melbourne, Australia. Assembling my participant group with the aid of five Australian and three Chinese universities and four commercial education agents in China, I interviewed 30 of my participants and some of their family members in various cities in China in June-July 2015, before their departure for Australia. I then met and interviewed a further 20 participants for the first time in Melbourne, where they had already commenced study, in July-August 2015. In order to gain a longitudinal perspective on how their experiences in Melbourne shape their subjectivity, I continue 
to spend regular time hanging out and chatting with this core group of 50 participants. The remaining six participants were part of a 15-person pilot study I completed in Melbourne in 2012: I interviewed them first then, and conducted follow-up interviews in 2015-16.

The majority of my participants' families belong to the professional, entrepreneurial, and managerial middle classes: what David Goodman refers to as the intermediate middle classes (2014: 116-120). Parents work in state or private enterprises as managers or in a range of professional roles including engineer, editor, designer, teacher, doctor, accountant, and media worker; some are also entrepreneurs running their own trading, manufacturing, or other small businesses. A handful are civil servants; an even smaller number - largely mothers - are non-professional employees. ${ }^{3}$ In line with state policy at the time of their birth, most participants are also only children and thus benefit from focussed parental investment in their education (Fong 2002). In this article, I focus on data gleaned from all stages of the study so far, including recorded initial interviews with participants and their family members, and recorded re-interviews of the pilot study participants, as well as the many non-recorded conversations I have had with core participants in the course of the study. Before engaging in detailed analysis of participant responses, I begin below by sketching out some social context for the post-1990 Chinese urban society where my participants grew up, focussing on significant developments in the social construction of youth.

\section{(Re)defining youth}

A number of demographic, cultural, and ideological developments that have occurred in China since the mid-twentieth century, and accelerated in urban areas since the 1990s, set the stage for changing experiences and understandings of life course, and youth in particular. While the conceptualisation of a distinct period of life between childhood and adulthood may be traced back through literary works as far as the late eighteenth century, the modern Chinese understanding of youth emerged around a century later, along with the development of a modern education system and a modernising urban intellectual culture in which youth (青年 qingnian) was framed as a driving force for cultural renewal (Clark 2012: 4). Following the 1949 Communist revolution, the qingnian concept became thoroughly imbricated with the political aims of the Chinese Communist Party (CCP), linked with the positive values of revolutionary vigour, idealism, and future orientation, while also functioning as a politico-demographic 
category in which young citizens were prepared for adulthood in the Party (Liu 2011: 5, Clark 2012: 5). Throughout much of the twentieth century, the term qingnian indicated a far wider sweep of years than the Western concept of 'youth', referring to an age range as wide as from the early teens to the mid-to-late-thirties (Liu 2011). As Paul Clark observes, however, by the 1990s, the concept of qingnian had become more narrowly defined, usually understood to refer to the period between adolescence and marriage (Clark 2012: 6; Kam 2012).

Indeed, arguably, the reforms era (after 1978) has ushered in a wholly new framework for understanding youth, qualitatively distinct from the qingnian concept of the high socialist period. First, this relates to the momentous ideological changes attendant on the shift from socialism to a market economy, especially the widespread valorisation, by both the state and commercial culture, of the self-enterprising subject whose centre of gravity is now located less in political consciousness than in the imperative to advance oneself in the capitalist economy (Zhang and Ong 2008; Liu 2011; Lewis, Martin and Sun 2016). Under this new ideological regime, youth - for both women and men - is popularly framed among middle-class urban dwellers as a time of 'striving' (拼 pin) to obtain the necessary academic qualifications, training, and capacities for self-management that will increase one's chance of success in the fiercely competitive job market, hence secure the economic foundation for one's own and one's family's future (Martin 2014). ${ }^{4}$

The changing meaning of youth in the Reforms Era should also be seen as the result of specific demographic shifts, especially in age at marriage and post-secondary education participation. In urban China, the average age at first marriage has risen steadily since 1990, largely reflecting a choice to marry later made by individuals and families, since direct government intervention in mandating the correct marriage age has significantly abated since 1980 (Cai and Wang 2014). Since in most of China social convention has long dictated that brides should be younger than grooms, rising age at first marriage has significant gendered ramifications. As Yong Cai and Wang Feng show in their detailed study of trends in age of first marriage between 1950 and 2005, across urban China increasing numbers of women, especially the highly educated, remain unmarried into their late twenties; and in Shanghai, 'among [...] the last 5 per cent [of women] to marry, age at first marriage has now reached a historical high [of about thirty]. A new era of delaying marriage has begun, starting with a group of pioneers' (Cai and Wang 2014: 104). If in contemporary usage, 'youth' is generally understood to refer 
to the period between adolescence and marriage, then the steadily rising marriage age in urban China suggests that youth is lengthening year by year, and for many urban women lasting into one's late twenties. In step with these shifts, James Farrer's research reveals that since the 1990s, in large metropolitan cities like Shanghai, new youth sexual cultures have emerged in which premarital sexual activity and relationships are becoming increasingly normalised (Farrer 2002; see further discussion below).

As Cai and Wang point out, 'delayed' marriage among urban women correlates positively with level of education (see also National Bureau of Statistics of China 2012: 26); and indeed, rising rates of tertiary education among both women and men provide an additional support for a 'stretched' youth period, since economic independence is delayed by longer study time. Like age at first marriage, tertiary education participation has been broadly trending upwards since the mid twentieth century (with a decade of disruption in 1966-1976 during the Cultural Revolution), but has followed an especially marked upward trajectory since the late 1990s. Over the past two decades, in line with the policy of growing the middle classes as a force for social stability (Goodman 2014: 111-114), China's government has massively increased its investment in higher education, so that by 2002 it had achieved $15 \%$ tertiary enrolment - the benchmark for the achievement of 'mass higher education' - and 19\% enrolment by 2004 (Bai 2006). Moreover, a few years later, women's enrolment in higher education reached, and then surpassed, parity with men's (World Bank 2016). Analysts connect this trend with the family politics of the single-child generations (born between 1978 - 2015): with no brothers to compete with, daughters of these generations enjoy unprecedented access to parental resources and hence educational opportunities (Fong 2002; Liu 2014). For both men and women, rising age at marriage and increasing participation in postsecondary education tend to extend the duration of youth; for women, however, this is especially significant since for them this period is socially shaped to be shorter than it is for men.

Taken together, these ideological, cultural, and demographic trends in urban China suggest that the experience and understanding of the years between adolescence and one's mid-to-late twenties may be undergoing significant change for the current generation of middle-class urban young women. It might suggest, perhaps, the appearance of a Chinese version of what developmental psychologists and others, following Jeffrey Arnett, call 'emergent adulthood' or a 'lengthening transition to adulthood': that is, a new and distinctive liminal life stage, roughly between the ages of 
18 and the mid-to-late twenties, which has arisen since the late twentieth century in industrialised societies where young people are afforded a period of self-focused identity exploration between adolescence and full adulthood (Arnett 2000; Arnett 2015;

Settersten and Ray 2010). Central to Arnett's concept of emergent adulthood is the idea of 'free' identity exploration: 'emerging adulthood is distinguished by relative independence from social roles and from normative expectations' (Arnett 2000: 469); it is 'the only period of life in which nothing is normative demographically' (Arnett 2000: 471 ) and 'a time not of settling into adult roles, but an exceptionally unsettled time' (Arnett 2015: 2).

Arnett's original theorisation of emerging adulthood noted explicitly that it may well be experienced by young people in urban areas in countries including India and China (2000: 478), and he speculates that it may spread globally with economic development. Following this lead, scholars from a range of disciplinary perspectives have sought to test the strength of the emerging adulthood concept in relation to young people in or from urban China, broadly concluding that signs of such a concept do appear to be present, albeit in somewhat distinctive versions (Badger, Nelson and Barry 2006; Nelson \& Chen 2007; Nelson, Badger \& Wu 2004; Farrer 2014b). For example, in their work on liberalising youth sexual cultures in the city of Hohhot, William Jankowiak and Robert L. Moore (2012) reproduce Arnett's association of emergent adulthood with increasing freedoms, proposing that indicators like increased sexual activity among college students, a conceptual delinking of sex from future marriage, and younger ages of first sexual activity show that China's youth are 'no longer constrained by social convention, [... and] are increasingly pushing the boundaries of social propriety' (2012: 290); and that this 'newfound personal freedom [is] typical of an emergent youth phase' (sic, 2012: 299). However, in what follows I address two questions that have remained under-explored in most of these extant studies. First, I am interested in the extent to which changing conceptualisations and experiences of this life period among middle-class urban Chinese women may be gender specific, and if so what role gender plays in shaping their experience of emerging adulthood, especially its purported 'freedoms' (or lack thereof). Second, I explore the impact that transnational educational mobility may have on such women's negotiation of this (gendered) life stage.

\section{Zone of suspension: Study abroad as time out from the normative gendered life course}

In our initial interviews, the majority of my study participants said that they 
expected to get married, and that sometime between the ages of 25 and 30 would be the best time to do so. A handful, however, expressed more unconventional views and said that there was no ideal age for marriage but rather one should let relationships take their natural course; or that they hoped to remain unmarried, or at least could accept it; or that other alternatives - marriage in middle age, de facto relationships, career taking precedence over marriage - would also be acceptable to them. While the majority tendency to assume the inevitability of marriage and the desirability of it happening before the age of 30 for women clearly indicates that these young women are influenced by the standard feminine life script in their society of origin, on the other hand, participants also quite often criticised the rigidity and normative force of that standard. Cihui, a 22 year-old from Shanghai coming to Melbourne to pursue a Masters degree in Accounting and Finance, made a succinct and representative statement that both summarises and critiques the currently normative Chinese feminine life course ideal:

Before, everyone felt, including parents, that when a woman was 20 she should do certain things, when she was 25 she should do certain things, when she was 30 she should do certain things. Like for example you graduate from university at 20, and from then until 25 you can start having boyfriends, falling in love, so that you definitely establish your family before you're 30: you establish your family at 28, so that by 30 you have a baby. [...] But now I think that a lot of women, including those in my own generation, born [...] around 1990 [...] don’t think that way. [...] They feel that work is more important: why [...] can’t you look for [family] after you're 30 , or get married a few years later?

Cihui's somewhat exasperated characterisation of the older generations' way of dividing women's lives into rigidly chronological stages centred around study then love then marriage then child(ren) was echoed in statements by many other participants. However, despite her frustrations with this 'old' way of thinking, Cihui stated that she did hope to marry in time to have her child(ren) before she was 30 (citing an extremely pervasive discourse that childbearing after age 30 entails significant health risks), and that if she had no fiancée by the time she was 25 , she would consider matchmaking (相亲 xiangqin). This equivocal accommodation between adherence to the normative model of feminine life course, and a critique of the discontents of that model, points to the 
contradictions in which this issue is currently embroiled in China's wider public culture (Wu 2009; Liu 2014).

For some participants, some of the time, time abroad seemed to create a 'zone of suspension' - a “'time out” from the life course' (Griffiths, Rogers and Anderson 2013: 6) - in the sense that the full force of Chinese sex-gender norms vis-à-vis life course and relationships was somewhat suspended as a result of geographic distance. Time in Melbourne enabled these participants to work on a sense of themselves as selfanimating subjects embracing a fluid life script with an extended period of something superficially resembling 'emerging adulthood', including exploration of non-marital intimate relationships. Renegotiation of the normative life course in one's country of origin may, of course, be a general feature of most temporary or permanent migrant experience, particularly for younger migrants. My argument in what follows, though, is that for these mobile students, this is so in particular ways due to the rigidity and specific characteristics of the dominant feminine life course model among China's urban middle classes, which is marked by fixed chronological markers of proper states for each phase, makes non-marital sexual activity potentially risky for women, and (re)directs women toward a family-focused identity by age thirty. ${ }^{5}$ With regard to what specifically about their situation enables their rethinking of the meaning of feminine youth, although some have stated that they feel this is partly due to a kind of osmotic absorption of Australian sex-gender values, it seems equally if not more likely that the change results more simply from spending time away from China. Participants sometimes speak in broad terms about the 'different atmosphere' abroad, but in fact the majority don't have significant friendships with local students or consume much local media. When we discuss these topics, they tend to assume that the dating and gender cultures among locals are more or less similar to what they see in US media, but several have sought my confirmation on this point, since they have had no direct experience of how local peers approach intimate relationships.

Before exploring the 'zone of suspension' in detail, is important to remember that related developments also characterise some youth cultures in China's large cities and, for participants from such cities, may already be familiar. Moreover, the pattern of geographic mobility affording a partial suspension of one's home society's norms of gender and sexuality may also apply to mobile youth within China. Farrer's extensive research on youth sexual cultures in Shanghai shows how what he calls a 'sexual revolution' in the 1990s began to normalise premarital sex and serial sexual 
relationships for both women and men (Farrer 2002, 2014a, 2014b). These developments somewhat decouple sexuality from marriage, while nonetheless failing to overthrow entrenched gendered scripts such as the cultural valuation of female sexual conservatism and bridal virginity (Farrer 2002: 223-257). One factor in the development of the increasingly 'open' (开放 kaifang) youth sex cultures that Farrer describes in China's large cities is the commonness of domestic geographic mobility. In the reforms era, youth of all classes begin to migrate on an unprecedented scale toward big cities in search of economic opportunity, leading to the dilution of parental authority (Jankowiak and Moore 2012: 279; Nyíri 2010). In the case of Chinese young people travelling abroad for study a parallel logic seems probable, such that existing trends in metropolitan China toward youth as a period of sexual exploration may be extended and accelerated by time away (see also Farrer 2002: 168).

For some of my study participants, then, living overseas indeed seems to bring a certain relaxing distancing from the pressures of home, and the development of a greater sense of personal autonomy over decision making, both in relationships and in broader life plans: a 'zone of suspension' in relation to time, space, and regulatory structures (Robertson 2013: 7). Like Song, cited at the beginning of this paper, who saw her time in Melbourne during her late teens and early twenties as a time when 'anything could happen', several other participants also characterised their time away as a time of radical openness, where future directions that may once have seemed clear grew uncertain. For example Niuniu, a 23 year-old from Henan province studying toward her Masters in Management (Accounting), mused:

With each life stage - like for example [between when] I'm 20 [and] 23 I'm studying [...]; then maybe after 23, you work for a couple of years, your parents start to get ideas; they think, you already have a steady job, you've already pretty much completed that part of your task, so you should start on the road to the next stage of your life. [...] [But] I think that being overseas entails more possibilities. That is, you have only a hazy image of what your future life might be, because you have more choices.

Niuniu's tone implied that she saw the 'haziness' of her future in a largely positive light: as an expansion of choices in this liminal time of educational mobility, more than a confusing lack of direction (Cwerner 2001: 27-28). Others made similar remarks. I first 
met Ying, from Hebei province and then 20 years old, in early 2012 when I conducted the pilot study for this project. Even then, just a few months after her arrival in Australia, she said that she hoped the more relaxed pace of life in Melbourne would help her realise her goal of leading a simpler, less stressful life than was possible in high-pressured Chinese society, savouring life's daily pleasures rather than engaging in ruthless competition for self-advancement. Four years later when we met again in 2016, Ying told me bluntly, 'I don’t really have like a blueprint for my future life. ${ }^{6}$ She described how on a recent trip back to China:

My Dad told me [that after living in Australia] I have no ambition anymore. Like [in China], everybody is struggling for like work, you know to get money to purchase a house or perhaps to get married. But I feel like, if I have a boyfriend and I love him, and he loves me, then that's OK, it doesn't matter; I don't think about, you know, [buying] a house. [...] Now, I feel like for everything: just let it be. But for the young me, it was more like: Oh, I have to get [to] this point, I have to get this goal. [...] [Whereas now] you don't have to be nervous; you don't have to be upset if you didn't [achieve the standard goals].

Ying's story links an attitude to one's life's progression (having 'ambition' or a 'blueprint' versus not) with gender and relationship norms (getting married and owning one's own home, versus having a relationship based purely on love). For Ying, her time in Melbourne has decoupled her desired life script from the goal-driven 'blueprint'. Ying now takes a more fluid and individualised view of both her life course and her intimate relationships, based strongly on her personal values: she emphasised throughout our recent conversation that she always puts herself at the centre of her life plans, and feels a responsibility first and foremost to herself in making decisions. Constructing Melbourne as the locus of individual freedom in opposition to China as the site of constraint by social norms and tradition, Ying told me: 'In Melbourne you can just be yourself. The way you want to be. But in China you have to fit [in with] others, or the very traditional ideology'.

Wenyi from Guangxi province was 24 when I first interviewed her in 2012, a few months after she arrived in Melbourne to undertake a Masters program in Accounting. She related to me in our first interview what she called the 'unhappy story' of the timing of her departure from China: she had wanted to work for a few years following her 
graduation, and then come to Australia, but her mother persuaded her to come immediately, before she was really ready to do so, in order not to derail the timing of her (hypothetical) marriage by age thirty (Martin 2014). By the time we spoke again four years later, Wenyi seemed to have defected - at least for the time being - from the life course her mother had planned for her. Still unmarried and working as an accountant in a Chinese-run business in Melbourne, living in a suburban share house with a group of young Australian professionals, Wenyi was hoping for her Permanent Residency to be granted soon. She had dated a Ghanian international student the year before, but the relationship broke up when he had to return to Ghana, and she was currently experimenting with meeting men on the Tindr dating app. Wenyi reflected:

I will see if I can stay in Australia longer cause I think Australia has [a] very interesting marriage status... Is that [called] 'de facto'? [...] It is a very interesting relationship. [...] I think I'll definitely get married at some point. That is the Chinese part in [me]. So I think in my life, I still need to try marriage, whether it can be successful or not, and then have children at some point. So that was my plan. But I just recently realised that there's this kind of [relationship called] de facto. [...] But still [...] I don't have a very concrete plan at the moment about my future, my job, my marriage and everything. I just think I should do that. I should do that. But I don't have a very specific plan or time frame at the moment. ${ }^{7}$

Wenyi's statements echo again the sense of haziness, uncertainty, and open possibility that we saw from other respondents above. She also sees herself as weighing up and hovering between two different systems for intimate relationships: marriage and children ('the Chinese part in me'), versus de facto relationships (which is something that 'Australia has'). As we have seen in some of the statements cited above, this connection of a fluid young-adult period ('I don't have a very concrete plan') with exploration of unconventional intimate relationships is relatively common within this group.

Several respondents commented on the fact that living in Melbourne, geographically and mentally removed from social and parental authority in China, effectively creates a zone of suspension of the standard gendered rules around relationships and intimacy that would apply if they had remained in China (see also Baas 2012: 140-144). Fenfang, 23, from Hebei, came to Melbourne to study toward her Master of Commerce. She had not had a boyfriend before arriving in Australia, but after 
a year in Melbourne, she met someone (also an international student from China) through a WeChat Chinese singles club: a privately organised weekly meet-and-greet digital chat group where young men and women can get to know each other for either serious dating or hook-ups. When I met Fenfang to chat about her new relationship about three weeks later, she said that they both really liked each other and were serious about the relationship, even planning to travel to China in the next university break to meet each other's parents. She felt that her boyfriend had been insinuating that they might move in together, extolling the liveability of certain suburbs in 'casual' conversation, as though they might soon start considering where to rent. Our conversation turned to the commonness of cohabitation (同居 tongju) among Chinese international students in Australia. 'It's totally common here!' said Fenfang. 'Among the couples I know, not one of them isn't living together!' Back in China, though especially in smaller cities like her hometown - the practice is far less usual. Before she left China, Fenfang said, she'd felt that she would want to be married before moving in with a partner. But now, she saw sense in the idea she'd heard from friends that before you get married, you should 'test out' whether you're compatible. She did worry, however: what if you move in together only to find you're not compatible? She had a friend in that situation, and her friend still felt bound to stick with her boyfriend despite their incompatibility, since if she cohabited with him but then broke up with him, she might appear morally 'loose' (随便 suibian). Fenfang thought that in her own case, her parents wouldn't necessarily oppose her moving in with her boyfriend, which echoes the attitude of parents of other respondents who have cohabited with boyfriends in Melbourne: some parents have been able to accept this happening in the overseas setting, on the condition that the relationship is very serious and likely headed for marriage. However, Fenfang underlined that if she did move in with her boyfriend, she would need to be 'extremely careful' about telling friends back home, because they might judge her morality and spread ugly rumours that could seriously damage her reputation and that of her family. She would therefore tend not to reveal the situation to any but her most deeply trusted friends in China.

Fenfang offered some interesting discussion of the different subjective feeling of sex-gender morality in her home city, versus in Melbourne:

There, you are constantly aware of the eyes of others on you, and what they may be thinking: you walk out your front door, and there are the neighbours - will they 
start up with 'Oh such a big girl like you, when will you find a fiancée?', 'Have you got a boyfriend yet?' You're just aware of that kind of pressure all the time, because your social network is wide, and tight-knit. Whereas here, you feel more free of it. What you think or do is what you want to think or do. You feel freer, you don't have that burden so much.

Fenfang discussed how Chinese students in Melbourne 'absorb the atmosphere' of Australian values on intimate relationships, but - as in her own story - also have to negotiate their continuing relationships with people back in China, who are immersed in a different moral scheme. With the ubiquitous transnational connectivity of mobile telephony and social media, young women like Fenfang are, in this sense, living, thinking, and planning transnationally, moment to moment, across two very different and in some ways contradictory social and cultural sex-gender systems, experiencing repeated cycles of asynchrony and partial resynchronisation of regimes of gendered time and value (Martin and Rizvi 2014; Robertson 2013: 136-148; Cwerner 2001: 22-23).

Fenfang's story is also interesting in a number of other ways. On one hand, it suggests that the experience of studying abroad enables a certain (partial) deinstitutionalisation of marriage (Cherlin 2004) and an experimentation with pre- or nonmarital intimate relationships that is possible, in significant part, due to the subjective distance from Chinese public opinion. This is not only about a distance from parental authority, as we have seen: pragmatic parents may actually support unconventional intimate practices such as premarital cohabitation, since the effective insulation that geographic distance offers from prying neighbours and extended family means that the young woman and her family are relatively secure from the risk of reputational damage. Distanced in this way from the dense web of moral surveillance that keeps young women's intimate relationships 'in line' at home, young women like Fenfang, Ying and others seem to experience a feeling of individualised 'freedom': 'What you think or do is what you want to think or do'. In this sense, life in Melbourne appears as a space for re-making the sex-gender rules - or accelerating changes already evident in some youth scenes in larger Chinese urban centres - and in the process, elaborating new meanings for feminine youth.

Intimate isolation and the persistence of normativity: The limits of gendered 'freedom' abroad 
Yet this freedom is far from total. Fenfang's account shows that even while living in Melbourne, she is far from unaffected by conventional Chinese gendered norms; for as Saulo Cwerner argues, 'times' - in this case, the time of the normative middle-class Chinese feminine life course - 'migrate with people' (2001: 7, emphasis in original). Her short relationship with her new boyfriend is already heading in a marriage-like direction, with parental introductions on the horizon. Moreover, the superficial 'freedom' of premarital cohabitation actually seems to present a minefield of gendered danger, with feminine reputational damage lurking everywhere: the inadvisability of cohabiting then breaking up; the danger of damaging rumours if social networks back in China get wind of the situation. These gendered limits to the zone of suspension are apparent, too, in Song's comments at the beginning of this paper, when she discusses entering a 'contradictory period' as, at 25 , she feels social expectation coming to bear on her with renewed force, pushing her to marry soon and settle down, despite her misgivings. Other respondents approaching their mid-twenties tell of mothers phoning them almost daily to push them to find a suitable fiancé and avoid being left on the shelf, causing the daughters significant stress and unhappiness. Meanwhile Ying, with her highly individualised worldview and explicit rejection of aspects of the normative life script in China, subsequently got back together with the ex-boyfriend of her teenage years. Despite being overall happy in this renewed relationship, she told me that does have some misgivings, finding her boyfriend somewhat controlling and too ready to fit in with social conventions that run against her own commitment to putting her own needs first. Nonetheless, although she had originally planned to further her studies to postgraduate level in Melbourne, Ying ultimately followed her boyfriend back to China, where he had a job in his father's business: 'I think that [following one's boyfriend] is something that girls always do,' she told me. Each of these examples shows how time away from China certainly does not bring definitive immunity from the pull of the normative feminine life script.

Xiaosu, a 20 year-old from Hunan province, contacted me saying that she urgently needed to talk with me as she'd just broken up with her boyfriend and was feeling upset. Xiaosu was at an all-time emotional low, largely as a result of this breakup. She and her boyfriend had been together only a very short time when she decided to break up with him, having realised she didn't really want to be with him and had only agreed to go out with him out of loneliness. But because she had slept with him once the night before breaking things off - going along with his assertion that sleeping together was 'the 
western way of doing romance' (国外谈恋爱的方式 guowai tan lian'ai de fangshi) Xiaosu was covered in shame and regret, on one hand worried that the ex-boyfriend would spread ugly rumours about her, and on the other hand so ashamed of her behaviour that she felt she 'couldn’t face people' (见不得人 jianbude ren) and daren't see her friends. 'If my parents found out they'd kill me!' Xiaosu told me. 'You're the only one I've told. I daren't tell anyone else. I know for westerners this sort of thing is common, but in China, if people find out, they will remember this sort of thing and use it as a weapon against you.' Xiaosu discussed with me her own conflicted feelings. Sleeping with someone and then not continuing as a couple: was that OK, or did it make her a 'bad girl'? She was painfully torn between her own internal sense that she had simply made a mistake and was not inherently a bad person, and a pervasive sexgender morality that would frame her behaviour as immoral.

This sense of a double or split value scheme is a theme that runs strongly through many of the responses discussed above. As we have seen, it is often presented as a distinction between one's own, independent beliefs, and the values of 'society', 'other people', or 'people in China'. But as we see in the accounts of both Fenfang and Xiaosu, when the values in question are specifically connected with unmarried women's sexual behaviour, the gendered double-standard means that they may be left to deal with the complexities of their intimate lives alone, due to fears about reputation - paradoxically, this is the case even though many in this cohort of young women abroad may be collectively experiencing quite similar situations and issues. The intimate isolation bred from fears of reputational damage means that these women's emergent alternative value systems may not spread or grow easily among them as a group; hence the dominant feminine sexual morality remains hegemonic, despite the geographic distance that affords alternative versions a certain, albeit limited, space for development.

\section{Conclusion}

Stories like those I have examined highlight the need for caution in seeking to explain current transformations in Chinese youth cultures with reference to theoretical templates, like Arnett's emerging adulthood framework, that unreflexively characterise youth cultures as tending toward ever-increasing freedoms. In some respects - for example, the apparent normalisation of cohabitation and pre- or non-marital sexual relationships - the emergent sex-gender culture of the young Chinese women studying abroad whose stories I have related do clearly appear to break with the norms of their 
parental generation. Yet to characterise contemporary Chinese youth cultures - whether in China or abroad - as simply tending toward ever-increasing 'freedoms' fails to recognise how the dominant gender scripts of the reforms era continue to produce coercive forms of gendered normativity, as we have seen clearly in my examples. ${ }^{8}$ Hence this period of youth can hardly be seen, especially for young women - even for those living and studying away from China - as one of unfettered personal freedom beyond all normativity. As Foucault has taught us with regard to the history of sexuality, cultural change over time is not best conceptualised as progress toward an eventual freeing from all restrictive norms; instead, each era and context regulates identities and sexualities according to its own, historically specific logics (Foucault 1990). In the case of the young, mobile Chinese women whose stories I have presented, the internal logic that runs consistently through their accounts of their own experiences and conceptualisations of feminine youth is a one of deep and stubborn contradictions.

This article set out, first, to consider what role gender plays in shaping the experience of early adulthood for my participant group. My findings underline the fact that this generation of young, urban, middle-class Chinese women is caught between opposing models of the feminine life script. On one hand, the still-dominant gendered life stage model is characterised by fairly rigid chronological markers of appropriate activities and states for each phase, makes non-marital sexual activity dangerous for women, and directs women toward a family-focused identity by age thirty. On the other hand, an alternative, emergent and increasingly alluring life script is characterised by flexibility of timing in life transitions, self-development rather than family-focus as the central value, the de-linking of sexuality from marriage, and a greater diversity of life pathways for adult women.

This article's second key project was to investigate the impact of transnational educational mobility on Chinese women's negotiation of early adulthood. Since the opportunity-cost to women is higher than that to men in the normative model outlined above, there is more impetus for women - especially academically, professionally and personally ambitious ones - to elaborate alternatives. Educational mobility seems for some such women to represent a step toward living out an alternative: delaying or derailing a standard life course, and elaborating new forms of gendered youth identity. But as we have seen, the contradictions of both femininity and life script tend to be reconfigured, rather than neatly resolved, in the partial 'zone of suspension' that overseas study affords. 


\section{Works Cited}

Arnett, J. J., 2015. Introduction: Emerging Adulthood Theory and Research: Where We Are and Where We Should Go. In J. J. Arnett, ed. The Oxford Handbook of Emerging Adulthood. Oxford and London: Oxford University Press, 1-12.

Arnett, J. J., 2000. Emerging Adulthood: A Theory of Development From the Late Teens Through the Twenties. American Psychologist, 55 (5), 469-480.

Baas, M., 2012. Imagined Mobility: Migration and Transnationalism Among Indian Students in Australia. London, New York and Delhi: Anthem Press.

Badger, S., L. J. Nelson, and C. M. Barry. 2006. Perceptions of the Transition to Adulthood Among Chinese and American Emerging Adults. International Journal of Behavioral Development, 30 (1), 84-93.

Bai, L. 2006. Graduate Unemployment: Dilemmas and Challenges in China's Move to Mass Higher Education. The China Quarterly, 185: 128-144.

Cai, Y. and F. Wang, 2014. (Re)emergence of Late Marriage in Shanghai: From Collective Synchronization to Individual Choice. In D. S. Davis and S. L. Friedman, eds., Wives, Husbands and Lovers: Marriage and Sexuality in Hong Kong, Taiwan, and Urban China. Stanford: Stanford University Press, 97-117.

Cherlin, A. J., 2004. The Deinstitutionalization of American Marriage. Journal of Marriage and Family, 66: 848-861.

Clark, P., 2012. Youth in China: From Red Guards to Netizens. Cambridge: Cambridge University Press.

Cwerner, S. B., 2001. The Time of Migration. Journal of Ethnic and Migration Studies 27 (1), 7-36.

Farrer, J., 2014a. Love, Sex and Commitment: Delinking Premarital Intimacy From Marriage in Urban China. In D. S. Davis and S. L. Friedman, eds. Wives, Husbands and Lovers: Marriage and Sexuality in Hong Kong, Taiwan, and Urban China. Stanford: Stanford University Press, 62-96.

Farrer, J., 2014b. Youth and Sexuality in China: A Century of Revolutionary Change. In V. Mackie and M. McLelland, eds. Routledge Handbook of Sexuality Studies in East Asia. London and New York: Routledge, 150-161.

Farrer, J., 2002. Opening Up: Youth Sex Culture and Market Reform in Shanghai. Chicago and London: Chicago University Press. 
Fong, V. L., 2002. China's One-Child Policy and the Empowerment of Urban Daughters. American Anthropologist, 104 (4), 1098-1109.

Foucault, M., 1990. The History of Sexuality Volume 1: An Introduction [1978]. Translated by R. Hurley. London: Penguin.

Gaetano, A. 2008. Sexuality in Diasporic Space: Rural-to-Urban Migrant Women Negotiating Gender and Marriage in Contemporary China. Gender, Place and Culture 15 (6), 629-645.

Goodman, D. S. G., 2014. Class in Contemporary China. Polity: Cambridge.

Griffiths, M., A. Rogers and B. Anderson, 2013. Migration, Time and Temporalities: Review and Prospect. Centre of Migration Policy and Society (COMPAS) Research Resources Paper, March: 1-31.

Jankowiak, W. and R. L. Moore., 2012. China’s Emergent Youth: Gender, Work, Dating and Life Orientation. In B. Hewlett, ed. Adolescent Identity: Evolutionary, Cultural and Developmental Perspectives, New York and London: Routledge, 277-300.

Kam, L. Y. L., 2012. Shanghai Lalas: Female Tongzhi Communities and Politics in Urban China. Hong Kong: Hong Kong University Press.

Lewis, T., F. Martin and W. Sun., 2016. Telemodernities: Television and Transforming Lives in Asia. Durham and London: Duke University Press.

Liu, F., 2014. From Degendering to (Re)gendering the Self: Chinese Youth Negotiating Modern Womanhood. Gender and education 26 (1), 18-34.

Liu, F., 2011. Urban Youth in China: Modernity, The Internet and the Self. London and New York: Routledge.

Martin, F., 2014. The Gender of Mobility: Chinese Women Students' Self-Making Through Transnational Education,' Intersections: Gender and Sexuality in Asia and the Pacific, 35. http://intersections.anu.edu.au/issue35/martin.htm.

Martin, F. and F. Rizvi., 2014. Making Melbourne: Digital Connectivity and International Students' Experience of Locality.' Media Culture and Society 36 (7), 1016-1031.

National Bureau of Statistics of China, 2012. Women and Men in China - Facts and Figures 2012. http://www.unicef.cn/en/publications/comprehensive/2065.html. Nelson, L. J. and X. Chen., 2007. Emerging Adulthood in China: The Role of Social and Cultural Factors. Child Development Perspectives 1 (2), 86-91. 
Nelson L. J., S. Badger, and B. Wu., 2004. The Influence of Culture in Emerging Adulthood: Perspectives of Chinese College Students. International Journal of Behavioral Development 28 (1), 26-36.

Nyíri, P., 2010. Mobility and Cultural Authority in Contemporary China. Seattle and London: University of Washington Press.

Robertson, S. 2013. Transnational Student-Migrants and the State: The EducationMigration Nexus. Houndsmills and New York: Palgrave Macmillan.

Settersten Jr, R. A., and B. Ray., 2010. What's Going On With Young People Today? The Long and Twisting Path to Adulthood.' In The Future of Children 20 (1), $19-41$.

World Bank. 2016. School Enrollment, Tertiary (Gross), Gender Parity Index (GPI), China.

http://data.worldbank.org/indicator/SE.ENR.TERT.FM.ZSPlocations=CN

$\mathrm{Wu}$, X. 吴小英. 2009. 市场化背景下性别话语的转型 (Transition in Gender

Discourse in the Context of Marketization). 《中国社会科学》(Chinese Social Science), 2: 1-13.

Zhang, W., 2000. Dynamics of Marriage Change in Chinese Rural Society in

Transition: A Study of a Northern Chinese Village. Population Studies 54 (1), $57-69$.

Zhang, L. and A. Ong. 2008. Introduction: Privatizing China: Powers of the Self, Socialism from Afar. In L. Zhang and A. Ong, eds. Privatizing China: Socialism From Afar. Ithaca: Cornell University Press, 1-19.

\section{Endnotes}

'All respondent names are pseudonyms; some details have been altered to protect anonymity. Quotes from respondents have been translated from Mandarin by the author unless notes indicate otherwise.

${ }^{2}$ For a discussion of a related form of 'diasporic' sex-gender subjectivity among ruralto-urban migrant women workers in China, see Gaetano 2008.

${ }^{3}$ For a detailed discussion of the complexities of defining China' s 'middle classes,' see Goodman (2014): 92- 121. 
${ }^{4}$ I refer here to the intermediate stratum of the middle classes; the thinking of the elite and super-wealthy is arguably attended by fewer (or at least different) anxieties. The framing of youth as a time of pin is common among my respondents, but more pronounced among those from intermediate-middle rather than super-wealthy class backgrounds. For a detailed discussion of the complexities of defining the middle classes in China today, see Goodman 2014.

${ }^{5}$ It is possible that the gendered life course model observed is specific to the middle and elite classes; however, since the socio-economic prerequisites for extended overseas study preclude inclusion of significant numbers of lower-class women in this study, robust cross-class comparison is not possible. Anecdotal discussion by participants of lower-class and rural acquaintances and relatives, however, accords with extant research to suggest that the ideal feminine marriage age in those contexts is lower than among middle class urban families (Zhang 2000).

6 This discussion was conducted in English.

7 This discussion was conducted in English.

${ }^{8}$ Jankowiak and Moore's lack of reflexivity on gender inequality vis-à-vis youth sexual cultures is surprising, since elsewhere in the same article they make a direct critique of gender inequality in the employment market (2012: 286-87). Although Farrer also proposes the pertinence of the emerging adulthood concept to China's urban youth (2014b), elsewhere he is far more attendant to the ongoing limitations imposed by gender norms (eg Farrer 2002: 223-257); Farrer also underlines that he does not propose that the new youth sexual culture should be seen as exemplary of sexual liberation or youth rebellion (2002: 19). 